Sonia Taktak et al. $\quad$ ESI - Page 1

\title{
Reactivity of a ( $\mu$-oxo)( $\mu$-hydroxo)diiron(III) diamond core with water, urea, substituted ureas, and acetamide
}

Sonia Taktak, Sergey V. Kryatov, and Elena V. Rybak-Akimova*

Department of Chemistry, Tufts University, Medford, Massachusetts 02155

* To whom correspondence should be addressed. E-mail: elena.rybak-akimova@tufts.edu

UV-Vis studies. The synthesis of 1a yielded in different batches green or maroon solids. The UV-Vis spectra of either solid in dry acetonitrile are identical. However, the corresponding solid UV-Vis spectra are different.

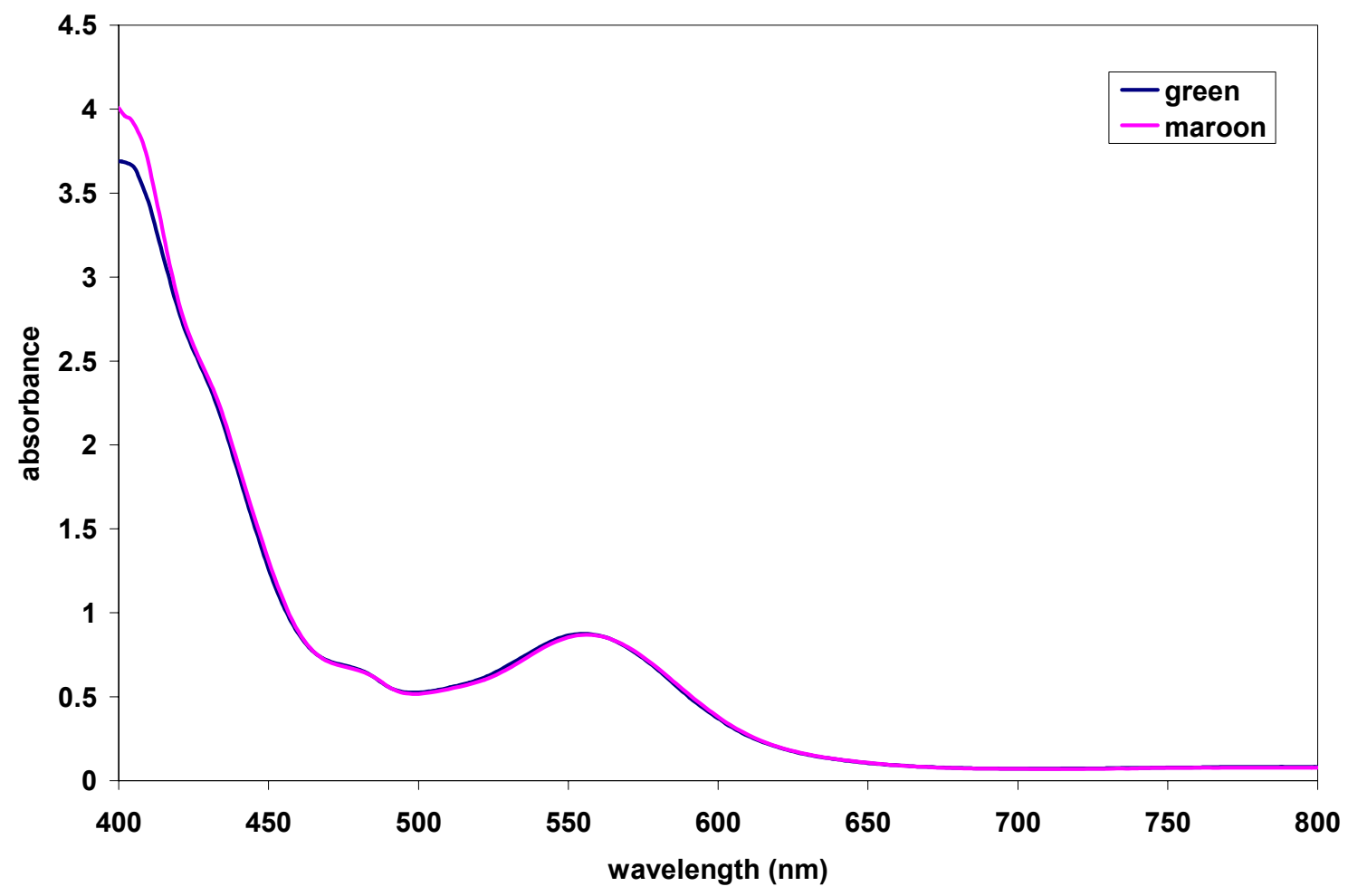

Figure S1. Solution UV-Vis $(1 \mathrm{mmol} / \mathrm{L}$ of green $1 \mathbf{a}$ and maroon 1/1a mixture in dry acetonitrile). The predominant species in solution is $\mathbf{1}$. 


\begin{tabular}{|l|l|l|l|}
\hline$\varepsilon\left(\mathrm{L} \cdot \mathrm{mol}^{-1} \cdot \mathrm{cm}^{-1}\right)$ & Maroon solid & Green solid & $\mathbf{1}$ - Ref 23 \\
\hline $430(\mathrm{sh})$ & 2357 & 2313 & 2072 \\
\hline 477 & 685 & 678 & 650 \\
\hline $512(\mathrm{sh})$ & 565 & 568 & 540 \\
\hline 555 & 886 & 863 & 702 \\
\hline
\end{tabular}

Table S1. Comparison of electronic spectra in acetonitrile with literature values.

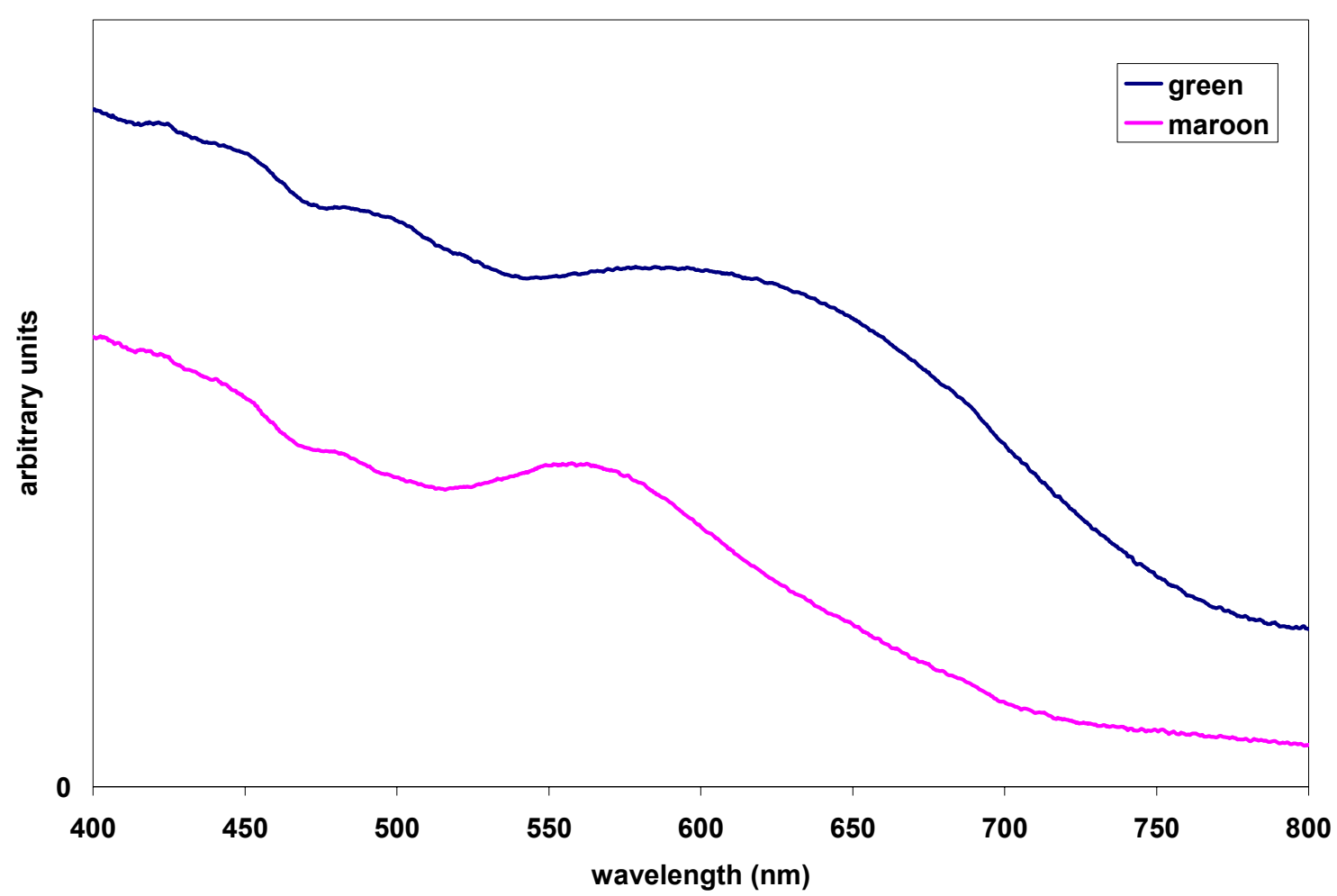

Figure S2. Solid UV-Vis (by measurement of reflectance of pure solid sample) of green 1a and maroon 1/1a mixture. In the solid state, the spectrum of the maroon solid resembles more that of pure 1 with slightly less well defined band at $\lambda=555 \mathrm{~nm}$ indicating the presence of small amounts of the hydrated form 1a. 


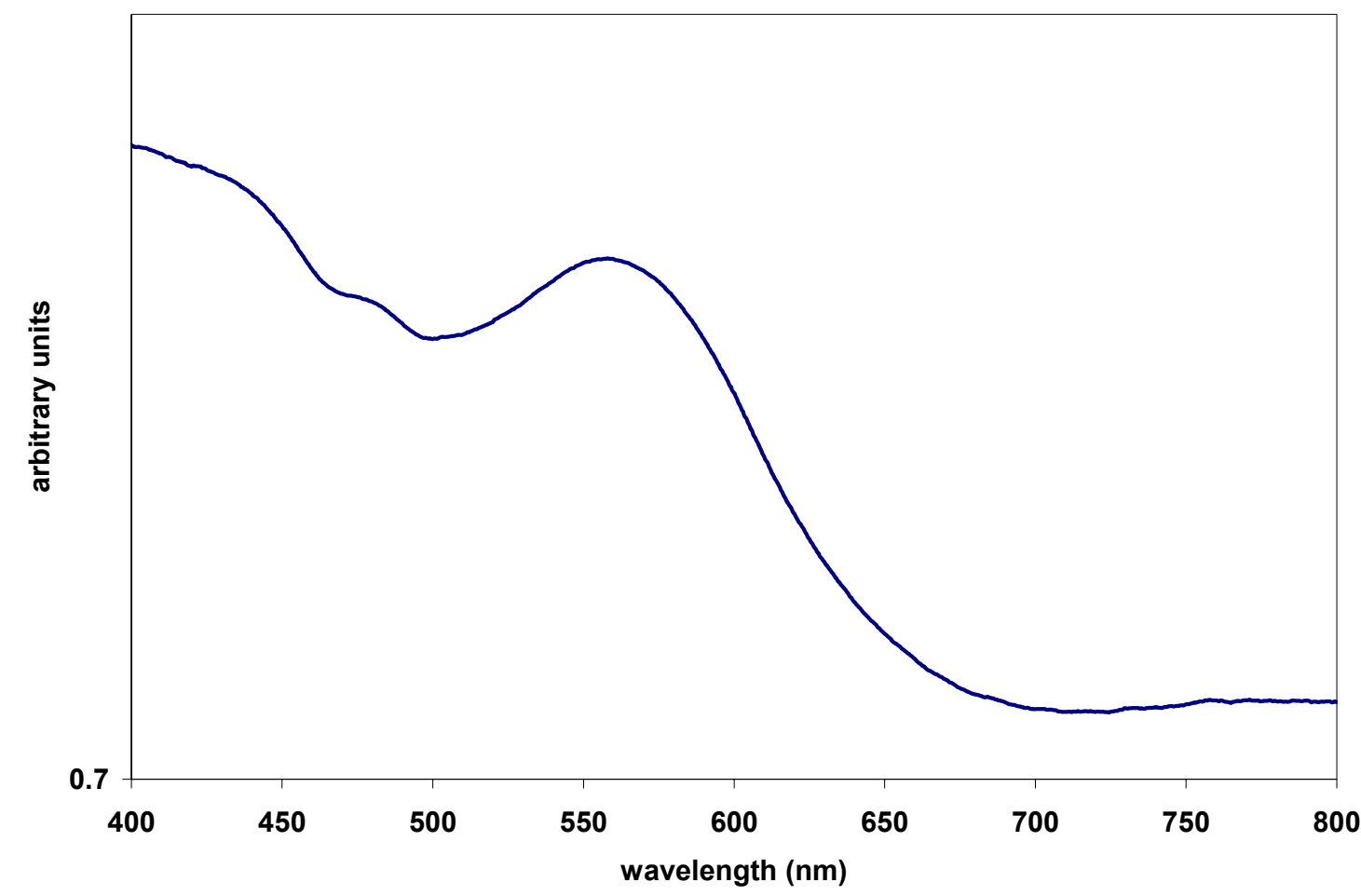

Figure S3. Solid UV-Vis by measurement of reflectance of pure crystals of $\mathbf{1}$.

In situ electrospray mass spectrometry - Reaction between 1 and 1,1-dimethylurea.

ST 040210a_040210095916 \#214-277 RT: 0.42-0.78 AV: 64 NL: $1.11 \mathrm{E} 6$

T: ITMS + p ESI Z ms [ 150.00-450.00]

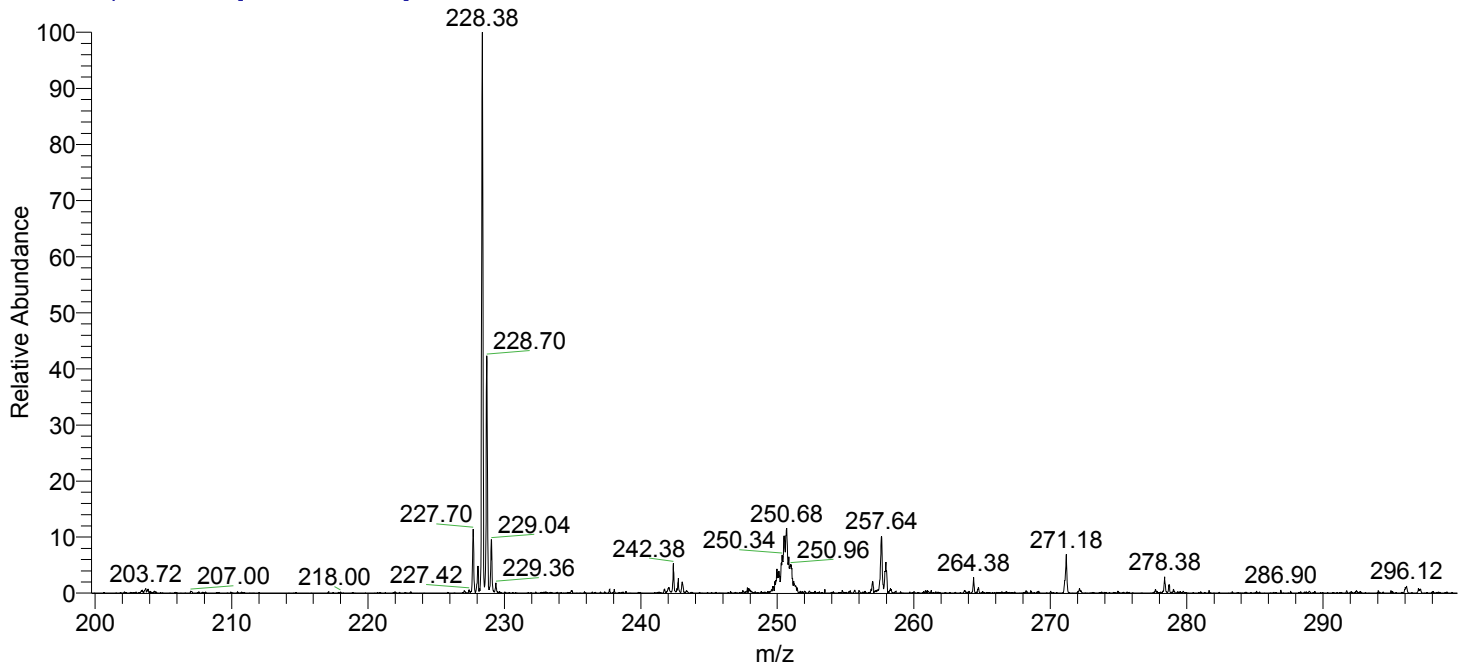

Figure S4. Mass spectrum of 1 in acetonitrile showing a $100 \%$ peak at $\mathrm{m} / \mathrm{z} 228.4$ corresponding to $\left\{\left[\mathrm{Fe}_{2}(\mu-\mathrm{O})(\mu-\mathrm{OH})(\mathrm{BPMEN})_{2}\right]\right\}^{3+}$. 
ST 040210c_040210095916 \#309-373 RT: 0.60-0.96 AV: 65 NL: 7.66E5

T: ITMS + p ESI Z ms [ 150.00-450.00]

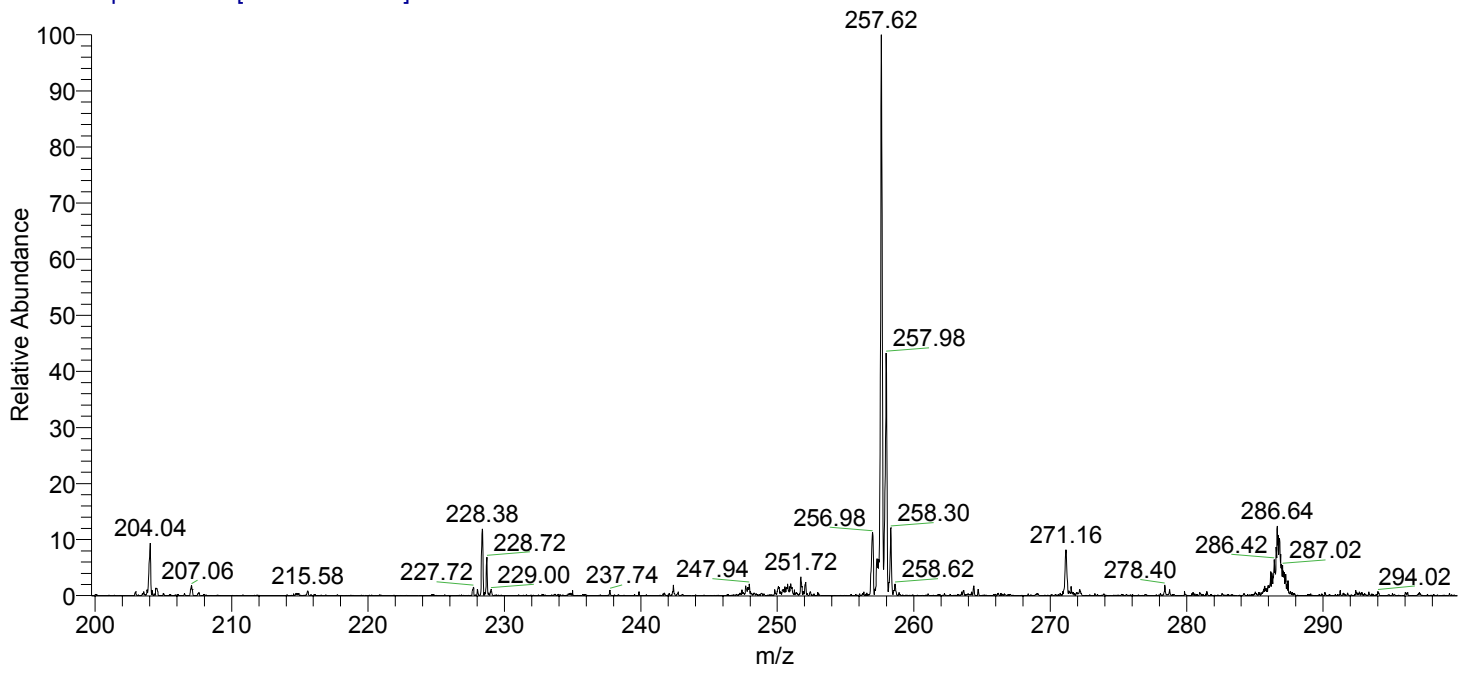

Figure S5. In situ mass spectrum after 10 minutes of reaction showing a $100 \%$ peak at $m / z 257.6$ corresponding to $\left\{\left[\mathrm{Fe}_{2}(\mu-\mathrm{O})(\mathrm{OH})\left(\mathrm{CO}\left(\mathrm{NH}_{2}\right)\left(\mathrm{N}\left(\mathrm{CH}_{3}\right)_{2}\right)\right)(\mathrm{BPMEN})_{2}\right]\right\}^{3+}$

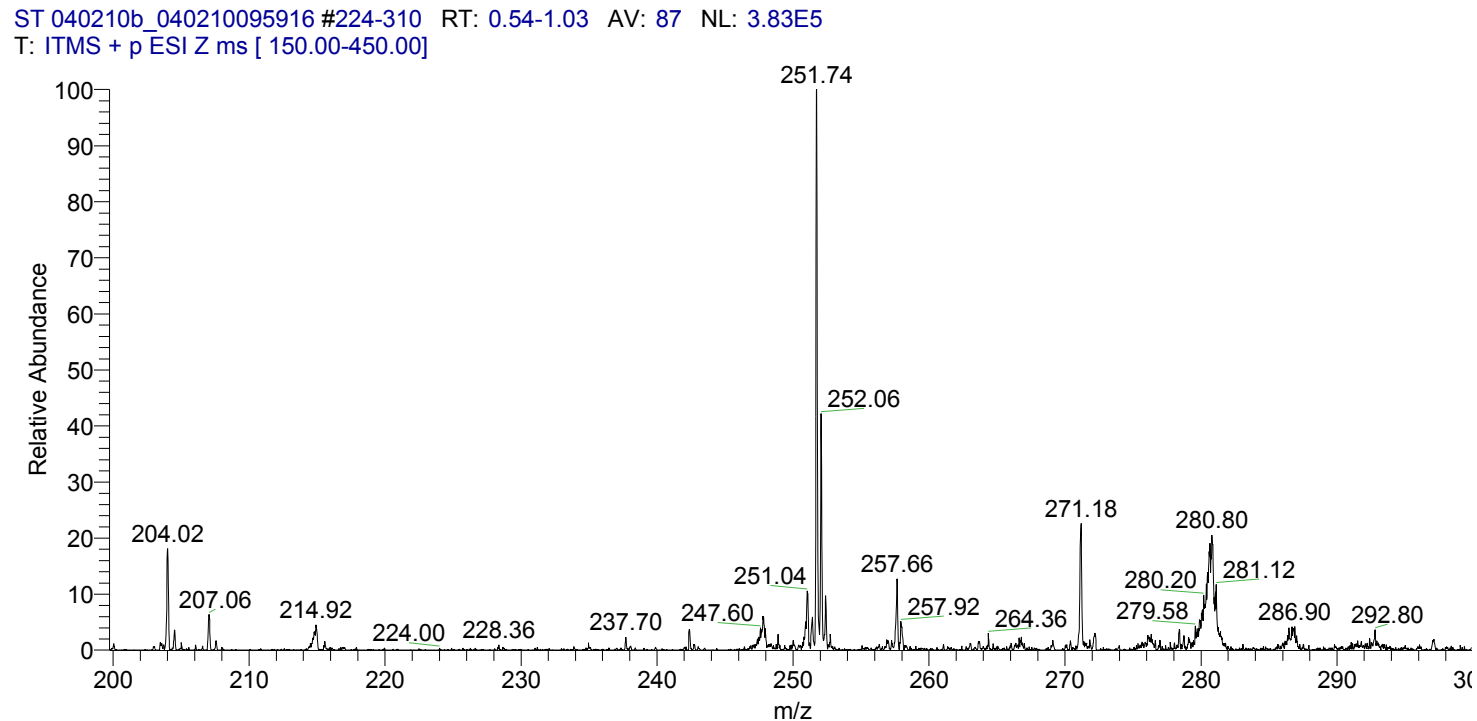

Figure S6. In situ mass spectrum after 14 hours of reaction with a $100 \%$ peak at $\mathrm{m} / \mathrm{z}$ 251.7 corresponding to $\left\{\left[\mathrm{Fe}_{2}(\mu-\mathrm{O})\left(\mathrm{CO}(\mathrm{NH})\left(\mathrm{N}\left(\mathrm{CH}_{3}\right)_{2}\right)\right)(\mathrm{BPMEN})_{2}\right]\right\}^{3+}$ 
Kinetic and thermodynamic parameters - Reaction between 1 and water - First step of the reaction between 1 and urea, a series of methylated ureas, and acetamide.

rate constants versus water conc at different temperatures

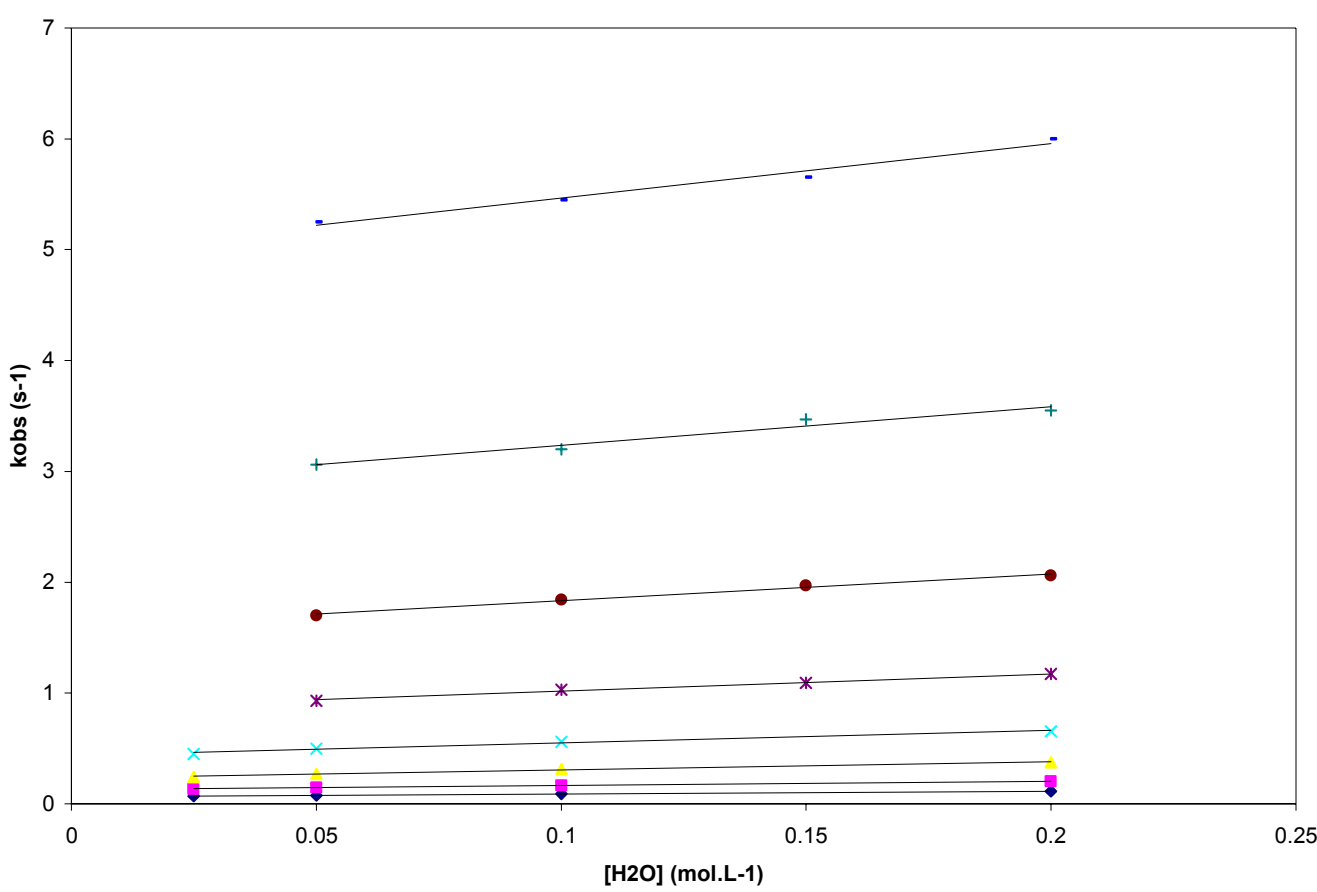

Figure S7. Reaction of 1 with water, studied by stopped-flow technique at different temperatures $-\mathrm{T}=5^{\circ} \mathrm{C}$ to $40^{\circ} \mathrm{C}$.
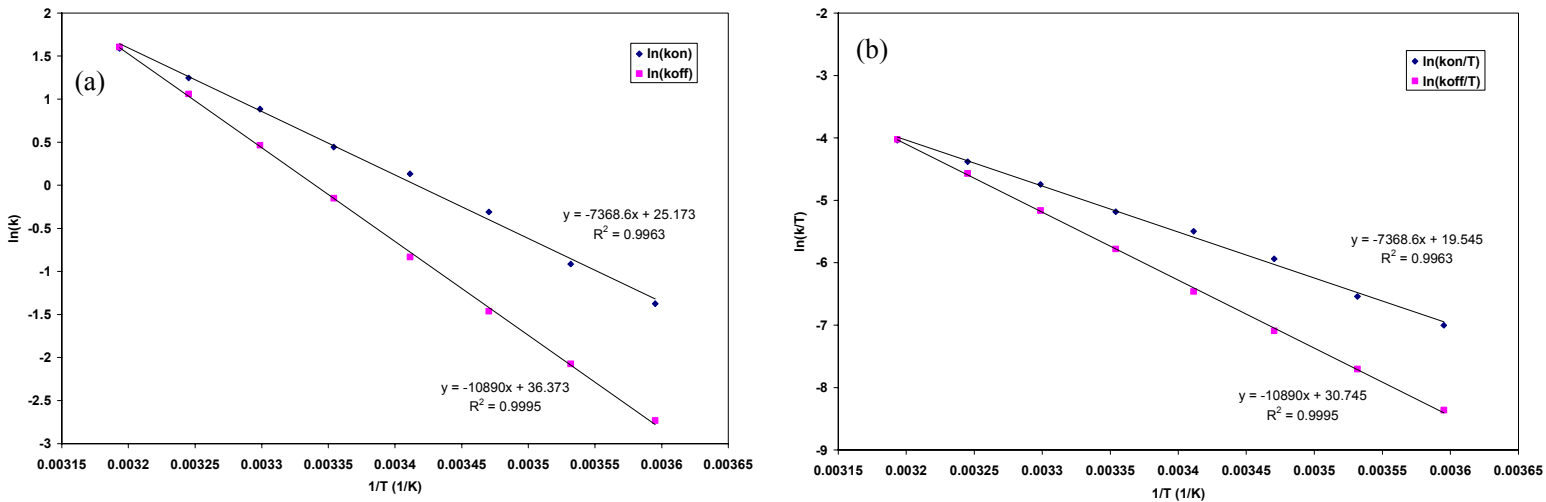

Figure S8. (a) Arrhenius plots for the forward and reverse reactions (b) Eyring plots for the forward and reverse reactions $-\mathrm{T}=5^{\circ} \mathrm{C}$ to $40^{\circ} \mathrm{C}$. 
rate constants versus $1-\mathrm{MeU}$ rea conc at different temp

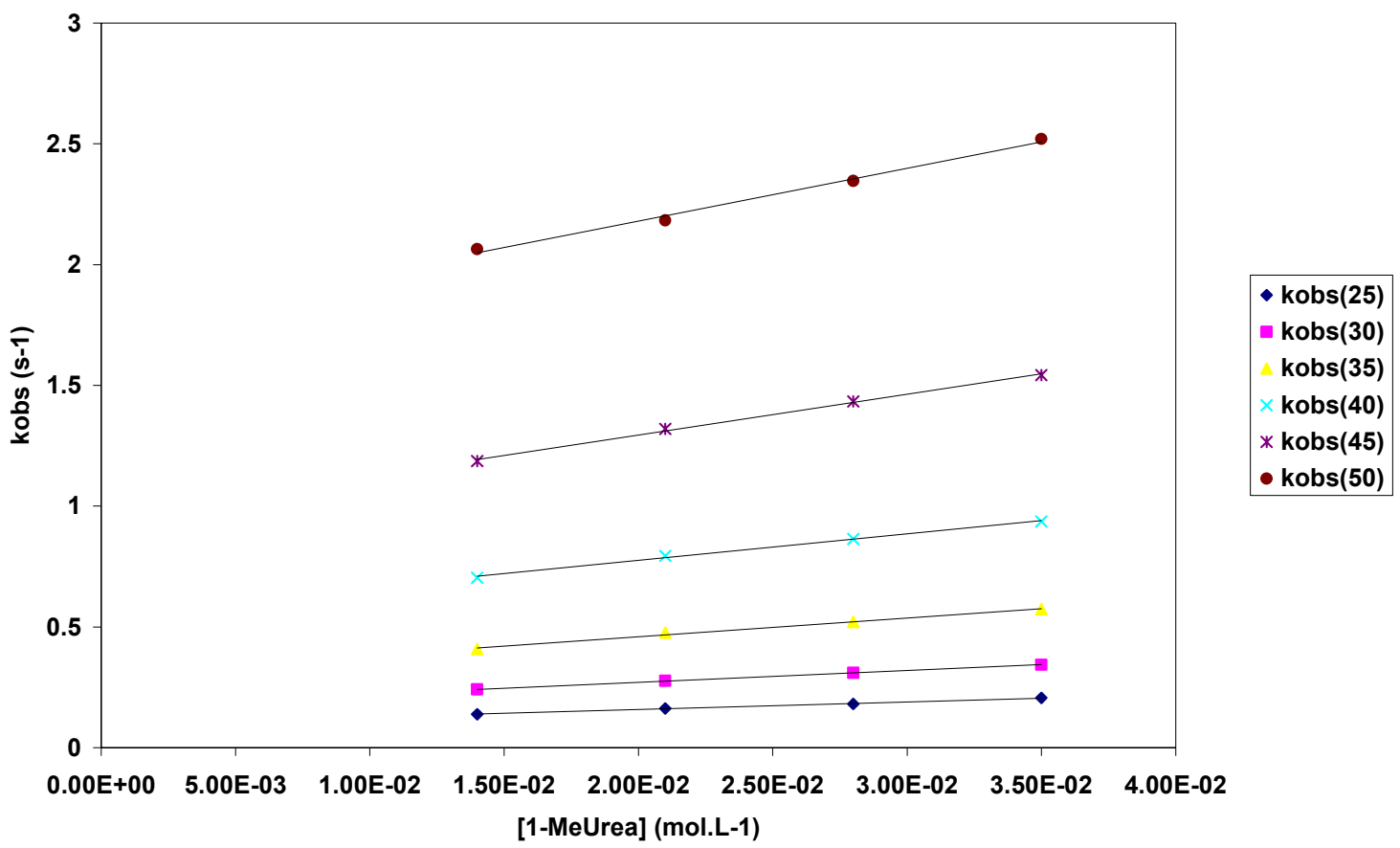

Figure S9. Reaction with 1-methylurea $-\mathrm{T}=25^{\circ} \mathrm{C}$ to $50^{\circ} \mathrm{C}$.

rate constants versus $1,3-M e U r e a$ conc at different temp

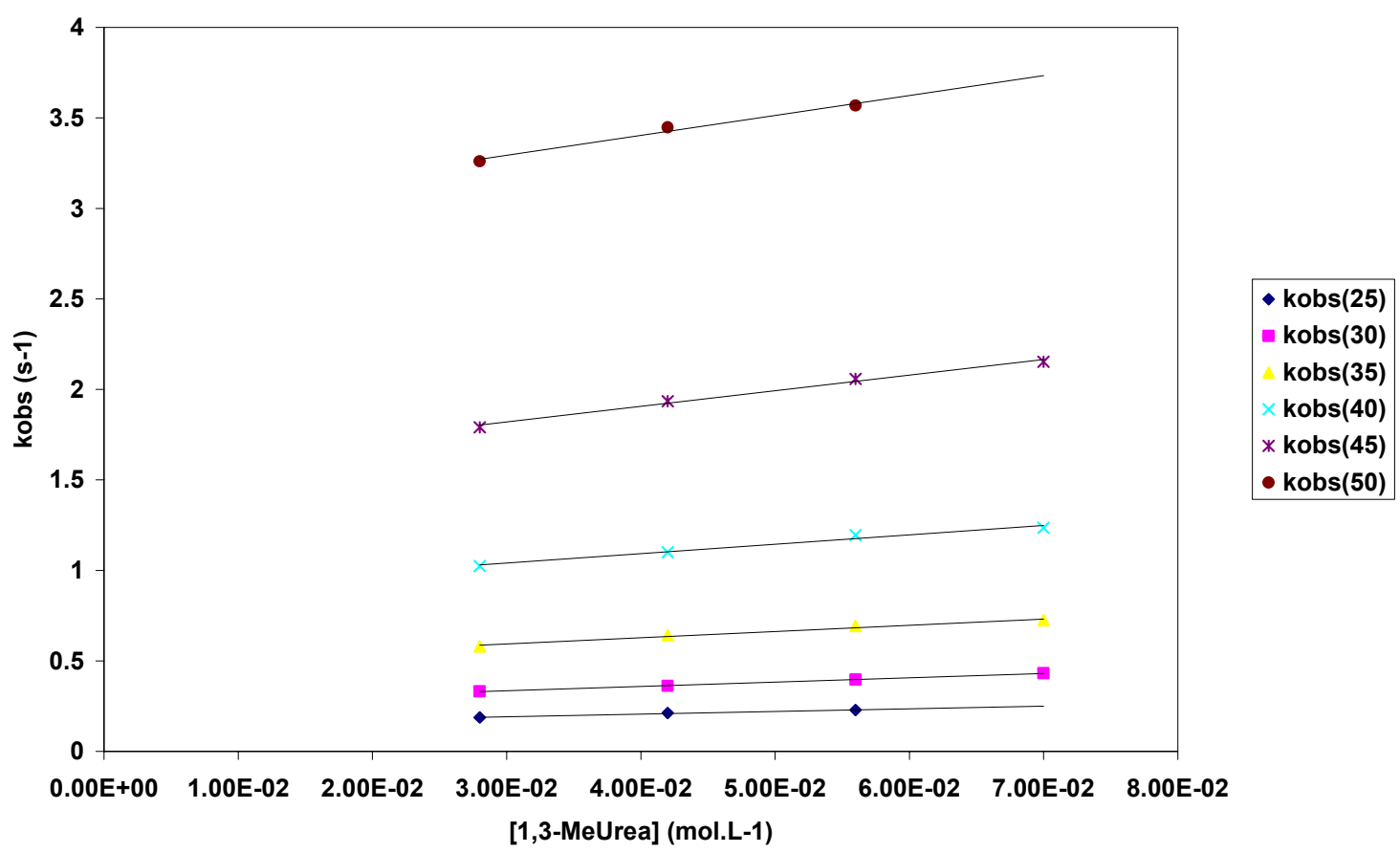

Figure S10. Reaction with 1,3-dimethylurea $-\mathrm{T}=25^{\circ} \mathrm{C}$ to $50^{\circ} \mathrm{C}$. 

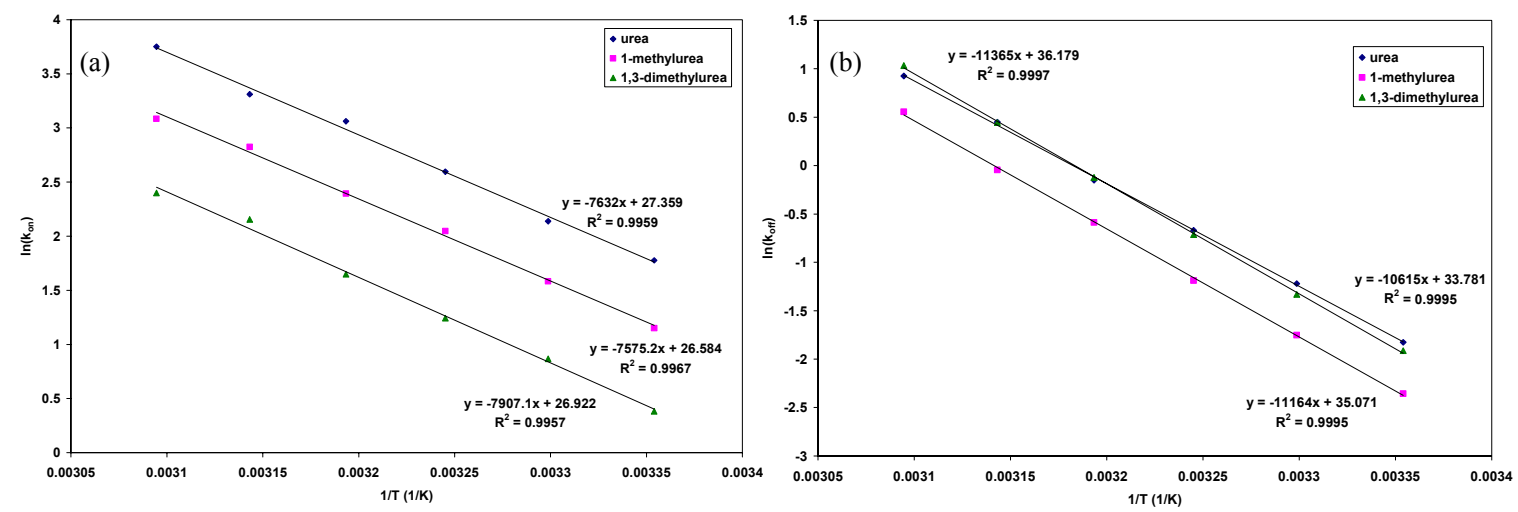

Figure S11. (a) Arrhenius plots for the forward reaction (b) Arrhenius plots for the reverse reaction $-\mathrm{T}=25^{\circ} \mathrm{C}$ to $50^{\circ} \mathrm{C}$.
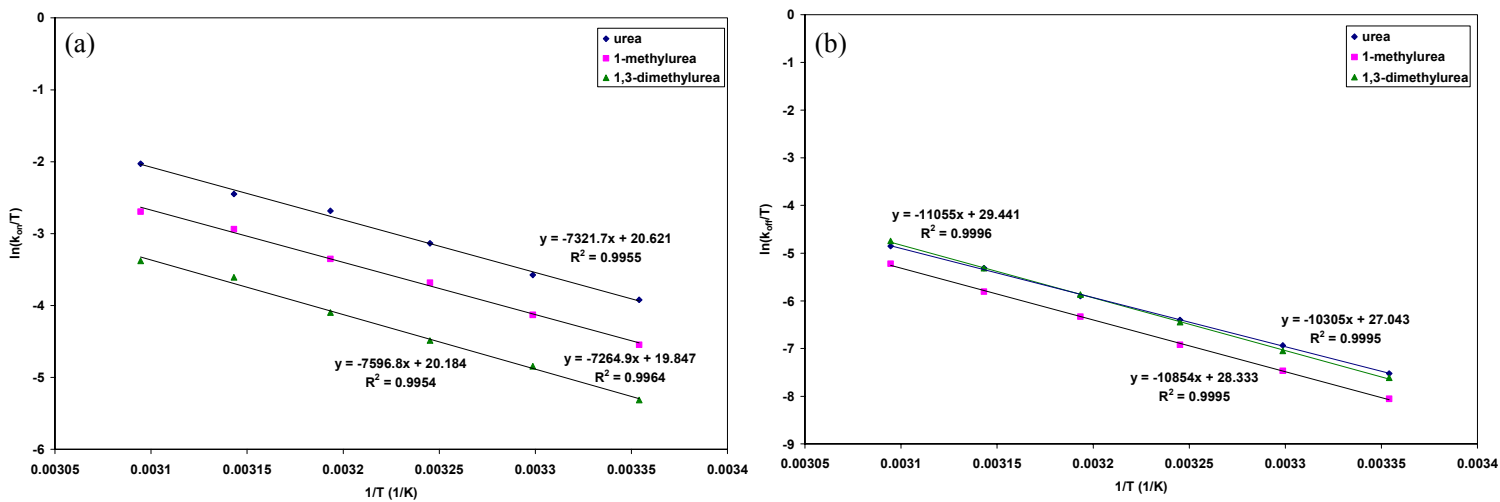

Figure S12. (a) Eyring plots for the forward reaction (b) Eyring plots for the reverse reaction $-\mathrm{T}=25^{\circ} \mathrm{C}$ to $50^{\circ} \mathrm{C}$. 
Pre-equilibrium study of the first step with acetamide and tetramethylurea.

Appropriate solutions of different concentrations in the incoming substrate were added to a solution of $\mathbf{1}$ in dry acetonitrile. UV-Vis spectra were recorded after mixing.

- For acetamide, the extinction coefficient of the ring opened species can not be measured directly since a second process of ring closure occurs. The model used to study this preequilibrium is as follow:

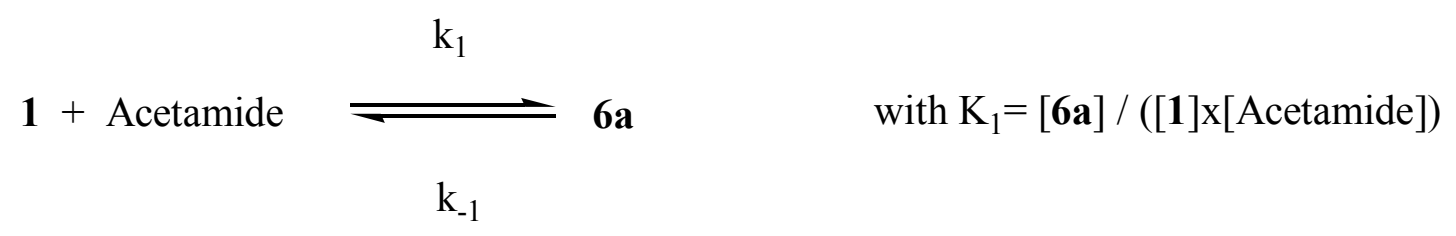

With this simple model, $\varepsilon=\varepsilon(\mathbf{6 a})+\left(1 / \mathrm{K}_{1}\right)(\varepsilon(\mathbf{1})-\varepsilon) /[$ Acetamide] with $\varepsilon=$ extinction coefficient at equilibrium, $\varepsilon(\mathbf{6 a})=$ extinction coefficient of the intermediate $\mathbf{6 a}, \varepsilon(\mathbf{1})=$ extinction coefficient of the precursor 1 and [Acetamide] the concentration of acetamide after mixing. Therefore $\mathrm{K}_{1}$ was directly deduced from the plot of $\varepsilon$ versus $(\varepsilon(\mathbf{1})-$ $\varepsilon) /[$ Acetamide]. Concentrations of acetamide were varied from 7 to $50 \mathrm{mM}$ after mixing.

- For tetramethylurea, no ring closure occurs and $\varepsilon(\mathbf{T})$ was determined directly and used to calculate $\mathrm{K}_{1}$ ( $\mathbf{T}$ is the product of the reaction between $\mathbf{1}$ and tetramethylurea):

$$
\mathrm{K}_{1}=(\varepsilon-\varepsilon(\mathbf{1}) /\{(\varepsilon-\varepsilon(\mathbf{T}))[\text { tetramethylurea }]\}
$$

Concentrations of tetramethylurea between $40 \mathrm{mM}$ and $140 \mathrm{mM}$ after mixing gave similar equilibrium constants and the value reported in Table 4 and S3 is an average value. 


\begin{tabular}{|c|c|c|c|c|c|c|}
\hline $\begin{array}{l}\text { Incoming/leaving } \\
\text { ligand }\end{array}$ & Temp, K & water & urea & 1-methylurea & 1,1-dimethylurea & 1,3-dimethylurea \\
\hline \multirow[t]{10}{*}{$\mathrm{k}_{1}\left(\mathrm{M}^{-1} \cdot \mathrm{s}^{-1}\right)$} & 278 & $0.25 \pm 0.01$ & - & - & - & - \\
\hline & 283 & $0.40 \pm 0.02$ & - & - & - & - \\
\hline & 288 & $0.73 \pm 0.06$ & - & - & - & - \\
\hline & 293 & $1.1 \pm 0.1$ & - & - & - & - \\
\hline & 298 & $1.6 \pm 0.1$ & $5.9 \pm 0.2$ & $3.2 \pm 0.1$ & $6.7 \pm 0.5$ & $1.5 \pm 0.1$ \\
\hline & 303 & $2.4 \pm 0.2$ & $8.5 \pm 0.3$ & $4.9 \pm 0.1$ & - & $2.38 \pm 0.05$ \\
\hline & 308 & $3.5 \pm 0.5$ & $13.4 \pm 0.6$ & $7.7 \pm 0.4$ & - & $3.5 \pm 0.3$ \\
\hline & 313 & $4.9 \pm 0.5$ & $21.4 \pm 0.8$ & $11.0 \pm 0.5$ & - & $5.2 \pm 0.5$ \\
\hline & 318 & - & $27 \pm 1$ & $16.9 \pm 0.5$ & - & $8.6 \pm 0.6$ \\
\hline & 323 & - & $43 \pm 1$ & $22 \pm 1$ & - & $11.0 \pm 0.9$ \\
\hline$\Delta \mathrm{H}^{\ddagger}\left(\mathrm{kJ}^{\prime} \cdot \mathrm{mol}^{-1}\right)$ & & $61 \pm 2$ & $61 \pm 2$ & $60 \pm 2$ & - & $63 \pm 3$ \\
\hline$\Delta \mathrm{S}_{1}^{\ddagger}\left(\mathrm{J} \cdot \mathrm{mol}^{-1} \cdot \mathrm{K}^{-1}\right)$ & & $-43 \pm 1$ & $-25.2 \pm 0.7$ & $-31.7 \pm 0.8$ & - & $-29 \pm 1$ \\
\hline \multirow[t]{10}{*}{$\mathrm{k}_{-1}\left(\mathrm{~s}^{-1}\right)$} & 278 & $(0.65 \pm 0.01) \times 10^{-1}$ & - & - & - & - \\
\hline & 283 & $(1.25 \pm 0.02) \times 10^{-1}$ & - & - & - & - \\
\hline & 288 & $(2.31 \pm 0.07) \times 10^{-1}$ & - & - & - & - \\
\hline & 293 & $(4.3 \pm 0.1) \times 10^{-1}$ & - & - & - & - \\
\hline & 298 & $(8.6 \pm 0.1) \times 10^{-1}$ & $(1.61 \pm 0.05) \times 10^{-1}$ & $(0.95 \pm 0.03) \times 10^{-1}$ & $(1.83 \pm 0.04) \times 10^{-1}$ & $(1.48 \pm 0.06) \times 10^{-1}$ \\
\hline & 303 & $1.59 \pm 0.02$ & $(2.95 \pm 0.06) \times 10^{-1}$ & $(1.74 \pm 0.02) \times 10^{-1}$ & - & $(2.64 \pm 0.03) \times 10^{-1}$ \\
\hline & 308 & $2.89 \pm 0.07$ & $(5.1 \pm 0.1) \times 10^{-1}$ & $(3.0 \pm 0.1) \times 10^{-1}$ & - & $(4.9 \pm 0.2) \times 10^{-1}$ \\
\hline & 313 & $4.98 \pm 0.07$ & $(8.5 \pm 0.2) \times 10^{-1}$ & $(5.6 \pm 0.1) \times 10^{-1}$ & - & $(8.8 \pm 0.3) \times 10^{-1}$ \\
\hline & 318 & - & $1.57 \pm 0.02$ & $(9.6 \pm 0.1) \times 10^{-1}$ & - & $1.56 \pm 0.03$ \\
\hline & 323 & - & $2.52 \pm 0.03$ & $1.74 \pm 0.03$ & - & $2.81 \pm 0.05$ \\
\hline$\Delta \mathrm{H}^{\ddagger}{ }_{-1}\left(\mathrm{~kJ} \cdot \mathrm{mol}^{-1}\right)$ & & $90.5 \pm 0.8$ & $86 \pm 1$ & $90 \pm 1$ & - & $92 \pm 1$ \\
\hline$\Delta \mathrm{S}_{-1}^{\ddagger}\left(\mathrm{J} \cdot \mathrm{mol}^{-1} \cdot \mathrm{K}^{-1}\right)$ & & $49.7 \pm 0.5$ & $28.2 \pm 0.3$ & $38.9 \pm 0.4$ & - & $48.1 \pm 0.6$ \\
\hline
\end{tabular}

Table S2. Comparison of the kinetic parameters for water, urea, 1-methylurea, 1,1-dimethylurea and 1,3-dimethylurea interaction with complex 1. 


\begin{tabular}{|c|c|c|c|c|c|c|c|c|}
\hline $\begin{array}{l}\text { Incoming/leaving } \\
\text { ligand }\end{array}$ & Temp, K & water & urea & 1-methylurea & $\begin{array}{l}1,1- \\
\text { dimethylurea }\end{array}$ & $\begin{array}{l}1,3- \\
\text { dimethylurea }\end{array}$ & $\begin{array}{l}1,1,3,3- \\
\text { tetramethylurea }\end{array}$ & acetamide \\
\hline \multirow[t]{10}{*}{$\mathrm{K}_{1}\left(\mathrm{~L} \cdot \mathrm{mol}^{-1}\right)$} & 278 & $3.9 \pm 0.2$ & - & - & - & - & - & - \\
\hline & 283 & $3.2 \pm 0.2$ & - & - & - & - & - & - \\
\hline & 288 & $3.2 \pm 0.3$ & - & - & - & - & - & - \\
\hline & 293 & $2.6 \pm 0.3$ & - & - & - & - & - & - \\
\hline & 298 & $1.8 \pm 0.1$ & $37 \pm 2$ & $33 \pm 2$ & $37 \pm 3$ & $9.9 \pm 0.8$ & $1.2 \pm 0.1^{\mathrm{a}}$ & $19 \pm 2^{\mathrm{a}}$ \\
\hline & 303 & $1.5 \pm 0.1$ & $29 \pm 1$ & $28.1 \pm 0.5$ & - & $9.0 \pm 0.2$ & - & - \\
\hline & 308 & $1.2 \pm 0.2$ & $26 \pm 1$ & $25 \pm 2$ & - & $7.1 \pm 0.7$ & - & - \\
\hline & 313 & $1.0 \pm 0.1$ & $25 \pm 1$ & $19.7 \pm 0.9$ & - & $5.9 \pm 0.6$ & - & - \\
\hline & 318 & - & $17.5 \pm 0.7$ & $17.6 \pm 0.6$ & - & $5.5 \pm 0.4$ & - & - \\
\hline & 323 & - & $16.9 \pm 0.6$ & $12.5 \pm 0.8$ & - & $3.9 \pm 0.3$ & - & - \\
\hline$\Delta \mathrm{H}^{\mathrm{o}}\left(\mathrm{kJ} \cdot \mathrm{mol}^{-1}\right)$ & & $-29 \pm 2$ & $-25 \pm 2$ & $-30 \pm 2$ & - & $-29 \pm 3$ & - & - \\
\hline$\Delta \mathrm{S}^{\mathrm{o}}\left(\mathrm{J} \cdot \mathrm{mol}^{-1} \cdot \mathrm{K}^{-1}\right)$ & & $-93 \pm 1$ & $-53.4 \pm 0.8$ & $-70.6 \pm 0.9$ & - & $-77 \pm 1$ & - & - \\
\hline
\end{tabular}

${ }^{\mathrm{a}}$ constant determined by direct analysis of rapid equilibrium using regular UV-Vis techniques

Table S3. Comparison of the thermodynamic parameters for water, urea, methylated ureas and acetamide interaction with 1. 


\section{${ }^{1}$ H NMR studies in $\boldsymbol{d}$-acetonitrile.}

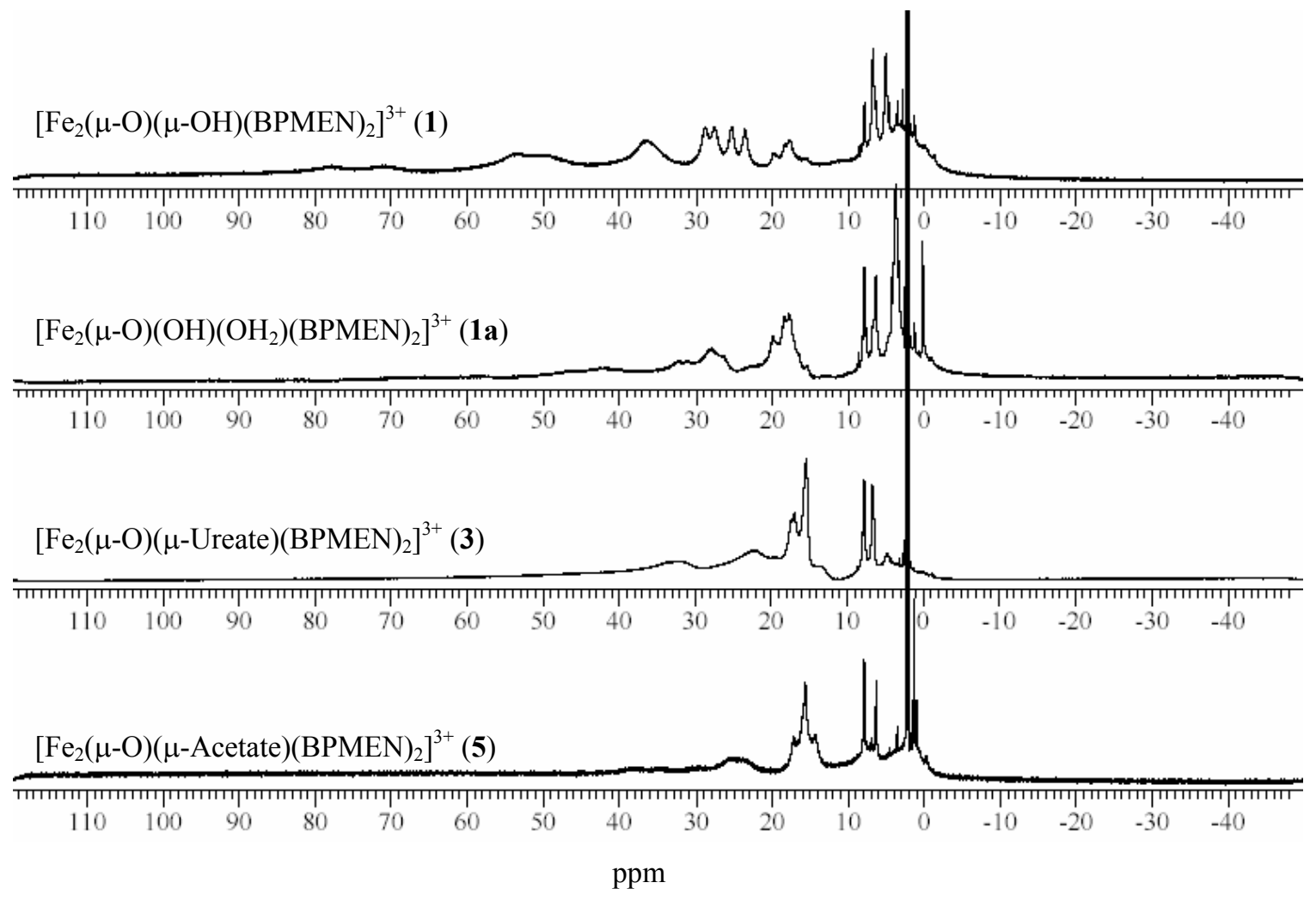

Figure S13. ${ }^{1} \mathrm{H}$ NMR spectra of 1, 1a (from $\mathbf{1}+100$ eq $\mathrm{D}_{2} \mathrm{O}$ ), $\mathbf{3}$ and $\mathbf{5}$. Spectra of 1a, 3 and $\mathbf{6}$ show paramagnetically shifted peaks over a narrower range than in the case of $\mathbf{1}$.

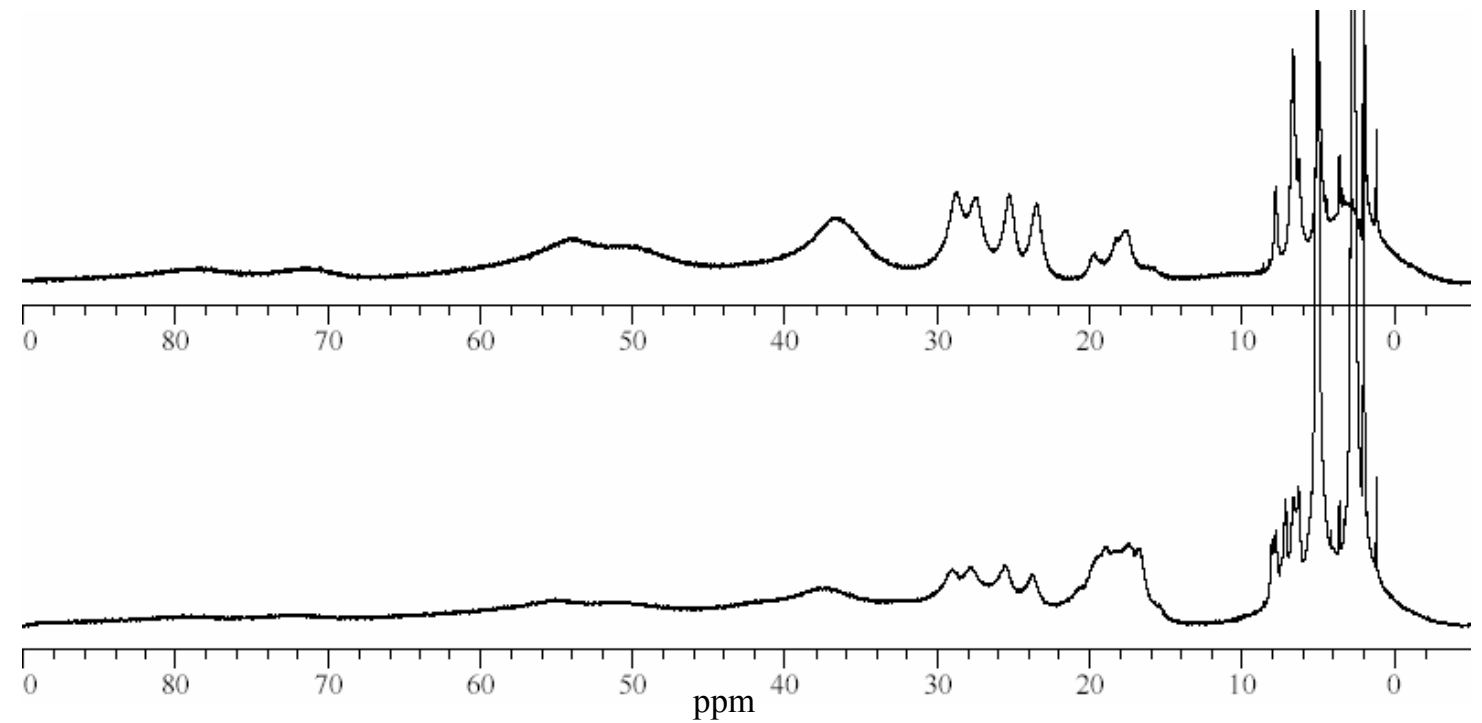

Figure S14. ${ }^{1} \mathrm{H}$ NMR of 1 and 1 with 3 equivalents of 1,3 -dimethylurea et $25^{\circ} \mathrm{C}$ in $d$ acetonitrile. 
Equilibrium study of the overall reaction with urea. Equilibrium (1) for the overall process of urea binding to 1 was studied in presence of 100 fold of water and different concentrations of urea ( 0 to 2 eq versus 1$)$.

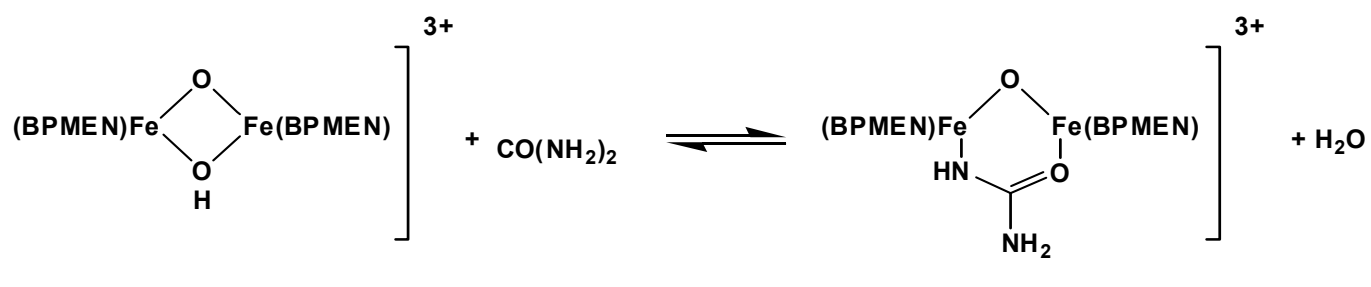

1

3

A $1 \mathrm{mM}$ solution of $\mathbf{1}$ and a $50 \mathrm{mM}$ solution of urea in dry acetonitrile were prepared under inert atmosphere. A $10 \mathrm{M}$ solution of water in acetonitrile was prepared under regular atmosphere. For each sample, 0 to $80 \mu \mathrm{L}$ ( 0 to $2 \mathrm{eq}$ ) of urea solution and $20 \mu \mathrm{L}$ of water solution were added to $2 \mathrm{~mL}$ of solution of 1 . Samples with no addition of water were also prepared as a control. The reaction was followed daily by UV-Vis until full equilibrium was reached after three days.

\section{equilibrium study}

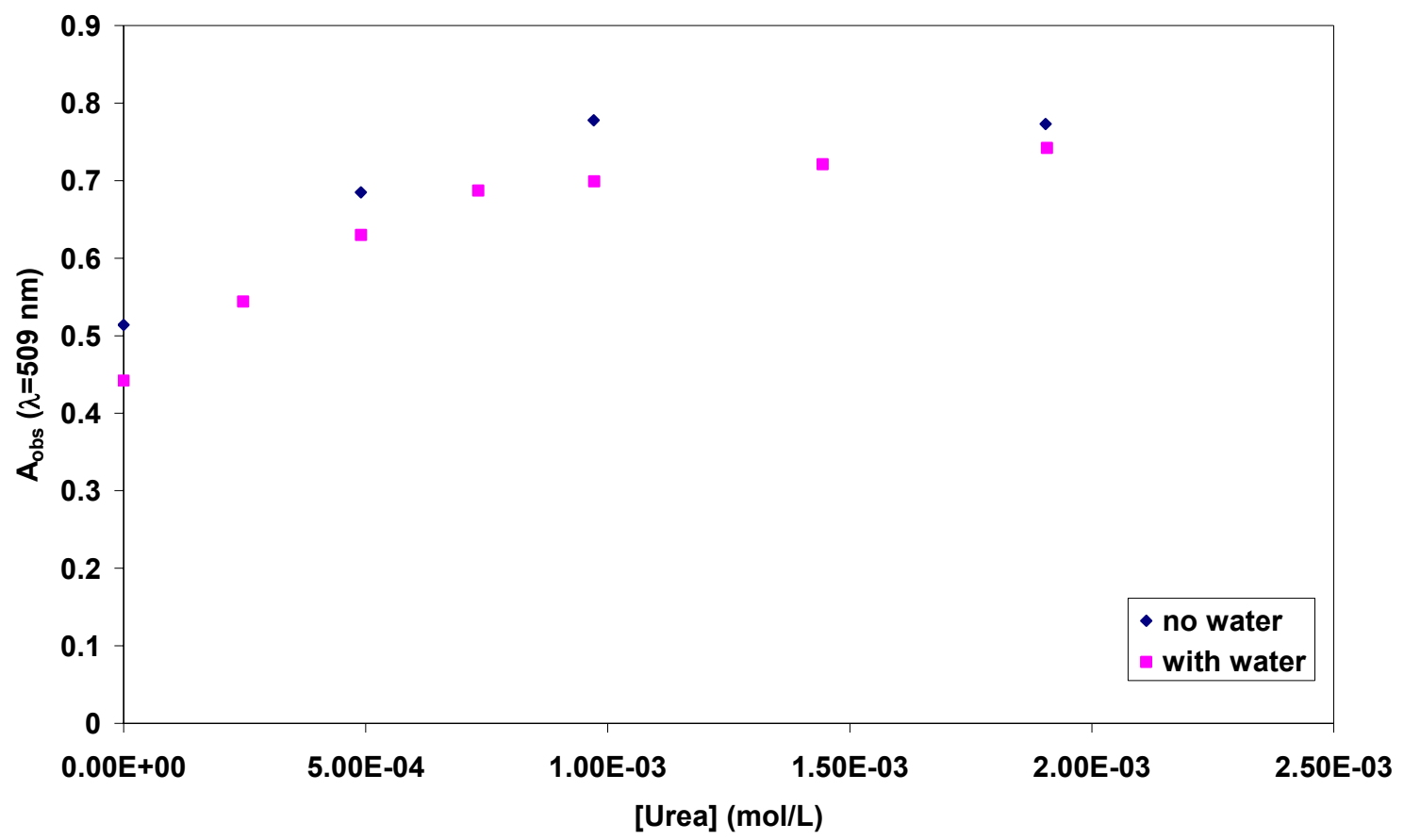

Figure S15. Plot of the absorbance at $\lambda=509 \mathrm{~nm}$ for equilibrium (1) in presence and absence of water at $25^{\circ} \mathrm{C}$ in acetonitrile. 
Since in the presence of water, complex 1 undergoes partial hydration to form 1a, the consumption of $\mathbf{1}$ by this side reaction was taken into account in the study of equilibrium (1) by correcting the relative concentration of urea versus $\mathbf{1}$.

A qualitative analysis of the UV-Vis spectra was done to determine the equilibrium constant $\mathrm{K}$. The expression used for this calculation is:

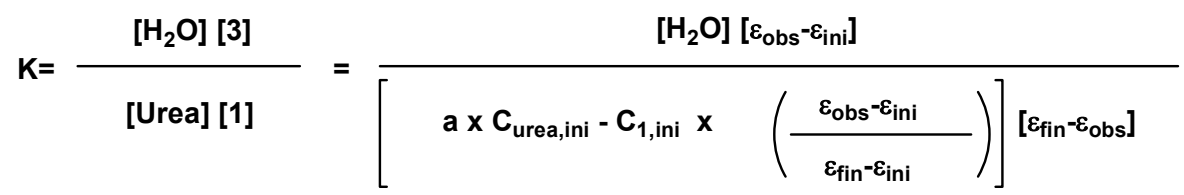

Where, for a specified wavelength, $\varepsilon_{\mathrm{obs}}$ is the experimental extinction coefficient, $\varepsilon_{\text {ini }}$ the initial extinction coefficient of $\mathbf{1}$ (calculated), $\varepsilon_{\text {fin }}$ the final extinction coefficient of $\mathbf{3}$ (calculated), $\mathrm{C}_{\text {urea,ini }}$ is the initial concentration of urea, $\mathrm{C}_{1 \text {,ini }}$ is the initial concentration of $\mathbf{1}$ and $\mathrm{a}$ is the correction factor (calculated) that account for the consumption of $\mathbf{1}$ by hydration. Dilution effects were taken into account in the calculation. The value of K was optimized by varying the parameters $\varepsilon_{\text {ini }}, \varepsilon_{\text {fin }}$ and a for three different wavelengths.

The average value for $\mathrm{K}$ was found to be about $600 \pm 70$, which is similar to the value of $650 \pm 100 \mathrm{M}$ obtained for the TPA system (ref 20).

\section{Urea hydrolysis studies}

- Experiment 1: a $10 \mathrm{mM}$ solution of $\mathbf{1}$ and a $70 \mathrm{mM}$ solution of urea in acetonitrile were prepared. 1 and urea were mixed (1:1) and (1:7) with and without 100 equivalents of water and left to react at $4{ }^{\circ} \mathrm{C}, 23{ }^{\circ} \mathrm{C}$ and $60{ }^{\circ} \mathrm{C}$. Blanks without 1 were also prepared (urea with and without water). $20 \mu \mathrm{L}$ aliquots were analyzed after 1 hour of reaction and $50 \mu \mathrm{L}$ aliquots after one day of reaction. Results: the calibration was good even when acetonitrile or 1 was present - All other tests were negative.

- Experiment 2: a $20 \mathrm{mM}$ solution of 1 was mixed with urea (1:1) in presence or absence of water (100eq) or sodium hydroxide (10eq). Blanks were prepared with addition of acetonitrile instead of $\mathbf{1}$. A solution of $\mathbf{3}$ was prepared and mixed with water and sodium hydroxide. A sample with 1 in presence of ammonia was also prepared (ratio $(1: 2)$ ). 
Samples were left at $60{ }^{\circ} \mathrm{C}$ in the oven overnight. $50 \mu \mathrm{L}$ aliquots were analyzed. Result: the calibration was good - only samples with sodium hydroxide or externally added ammonia had positive tests.

- Experiment 3: a $20 \mathrm{mM}$ solution of $\mathbf{1}$ in acetonitrile was prepared and distributed in 10 vials. An equal volume of $20 \mathrm{mM}$ solution of urea or $200 \mathrm{mM}$ acetamide was added at room temperature. In some cases where urea was present, an equimolar amount of sodium hydroxide or hydrogen peroxide was quickly added to the mixture. The corresponding blank samples were prepared with an equal volume of acetonitrile added instead of 1 . A calibration was performed at room temperature to test the solutions of the assay. The vials were left in the oven at $60{ }^{\circ} \mathrm{C}$ or at room temperature. $50 \mu \mathrm{L}$ aliquots were analyzed after 4 hours and after 24 hours. $100 \mu \mathrm{L}$ aliquots were also analyzed after three days at room temperature. Results: the calibration was good - all tests were negative except for the blank containing urea and sodium hydroxide $(1: 1)$ at $60{ }^{\circ} \mathrm{C}$ which had a slightly positive test.

- Experiment 4: solutions of 3 and urea in anhydrous acetonitrile $(10 \mathrm{mM})$ were prepared and mixed with various amounts, from 0 to $5 \mu \mathrm{L}$, of a concentrated solution of sodium hydroxide $(10 \mathrm{M})$. Blanks containing acetonitrile with the same amounts of sodium hydroxide were also prepared. A calibration was performed at room temperature to test the solutions of the assay. The vials were left in the oven at $60{ }^{\circ} \mathrm{C} .50 \mu \mathrm{L}$ aliquots were analyzed after 3 hours of reaction. Results: the calibration was good - at higher concentrations of sodium hydroxide (5 and 10 equivalents), a significant production of ammonia was detected in the blank. However, more ammonia was detected in samples containing urea or $\mathbf{3}$, with a maximum when urea is initially alone in solution.

Conclusion: Complex 1 shows no catalytic activity in the hydrolysis of urea in acetonitrile at temperatures ranging from 4 to $60{ }^{\circ} \mathrm{C}$. Only with an excess of sodium hydroxide (10 equivalents versus urea), a significant amount of ammonia was detected. However, sodium hydroxide was active as a promoter of urea hydrolysis even in absence of 1. Moreover, some acetonitrile also hydrolyses to a lesser extend under these conditions. The hydrolysis of ureate present in complex $\mathbf{3}$ does not occur faster than the hydrolysis of free urea. 